\title{
The Personnel Positioning Method of Underground Coal Mine
}

\author{
Ru Yandong, Xu Jie, Guo Jikun \\ College of Electronics and Information Engineering, Heilongjiang University of Science and Technology, Harbin, China
}

\section{Email address:}

10564006@qq.com (Ru Yandong)

\section{To cite this article:}

Ru Yandong, Xu Jie, Guo Jikun. The Personnel Positioning Method of Underground Coal Mine. International Journal of Oil, Gas and Coal Engineering. Vol. 6, No. 3, 2018, pp. 34-38. doi: 10.11648/j.ogce.20180603.11

Received: May 22, 2018; Accepted: June 7, 2018; Published: July 4, 2018

\begin{abstract}
The high cost, high Positioning precision or low Positioning precision are some questions of applying single staff Positioning method underground coal mine. The Positioning kind was divided into 3 kinds containing roadway, gab area and cavern. The beacon Layout scheme was adopted according to the characters of Positioning workplace. In the area of gab area, trilateral Positioning algorithm is applied. In the area of roadway and cavern RSSI was modified and centroid algorithm was adopted as trilateral Positioning algorithm's supplement. The test data demonstrates it can satisfy the underground coal mine demands.
\end{abstract}

Keywords: Personnel Positioning, Beacon Layout Scheme, Trilateral Positioning Algorithm, Centroid Algorithm

\section{Introduction}

The coal industry is the basic industry related to the sustainable development of the national economy. The coal mine and security management departments need to consider the production and safety management of underground miners, and require the miners working underground to be located and tracked. It will be convenient to check in, look for and monitor the underground personnel under normal conditions, especially in the event of mine disaster, which can help to rescue the trapped underground personnel more accurately. To reduce or even avoid casualties to protect underground workers is the main work in coal production safety [1]. The common underground positioning system of coal mine mainly adopts a single positioning method, but it does not aim at different underground geographical and electromagnetic environment [2]. According to the specific working environment of the underground, this paper adopts the different deployment strategy of beacon nodes, and chooses the appropriate positioning algorithm to achieve more efficient positioning.

\section{Underground Positioning System}

The spatial distribution of underground coal mine is extremely complex. In order to complete the positioning work, different positioning methods must be adopted according to different environment [3]. The underground is mainly composed of roadway, goaf and other functional areas represented by chamber (represented by chamber below). The roadway is a zonal distribution, which is divided into main roadway and branch roadway, and distributes tree-shaped underground. The total length of roadway can reach several hundred $\mathrm{km}$, some of which reach to thousands of $\mathrm{km}$ space to form strip. Coal mined-out area is rectangular distribution, the area is large, few people enter this area [4]. The chamber area is small having many equipment and material, the electromagnetic environment is complex [5]. It should consider the specific characteristics of the working environment for arranging positioning nodes. Layout diagram of underground positioning nodes are shown in figure 1 .

The active coordinator is mainly installed in the main lane and branch lane entrance, which is responsible for data transmission [6]. The passive coordinator is placed in the branch lane, goaf and auxiliary function area, which is responsible for setting up the positioning area, collecting data, forwarding data and transmitting the data to the active coordinator [7]. Beacon nodes are prearranged as fixed reference nodes, which are responsible for the localization of blind nodes [8]. 


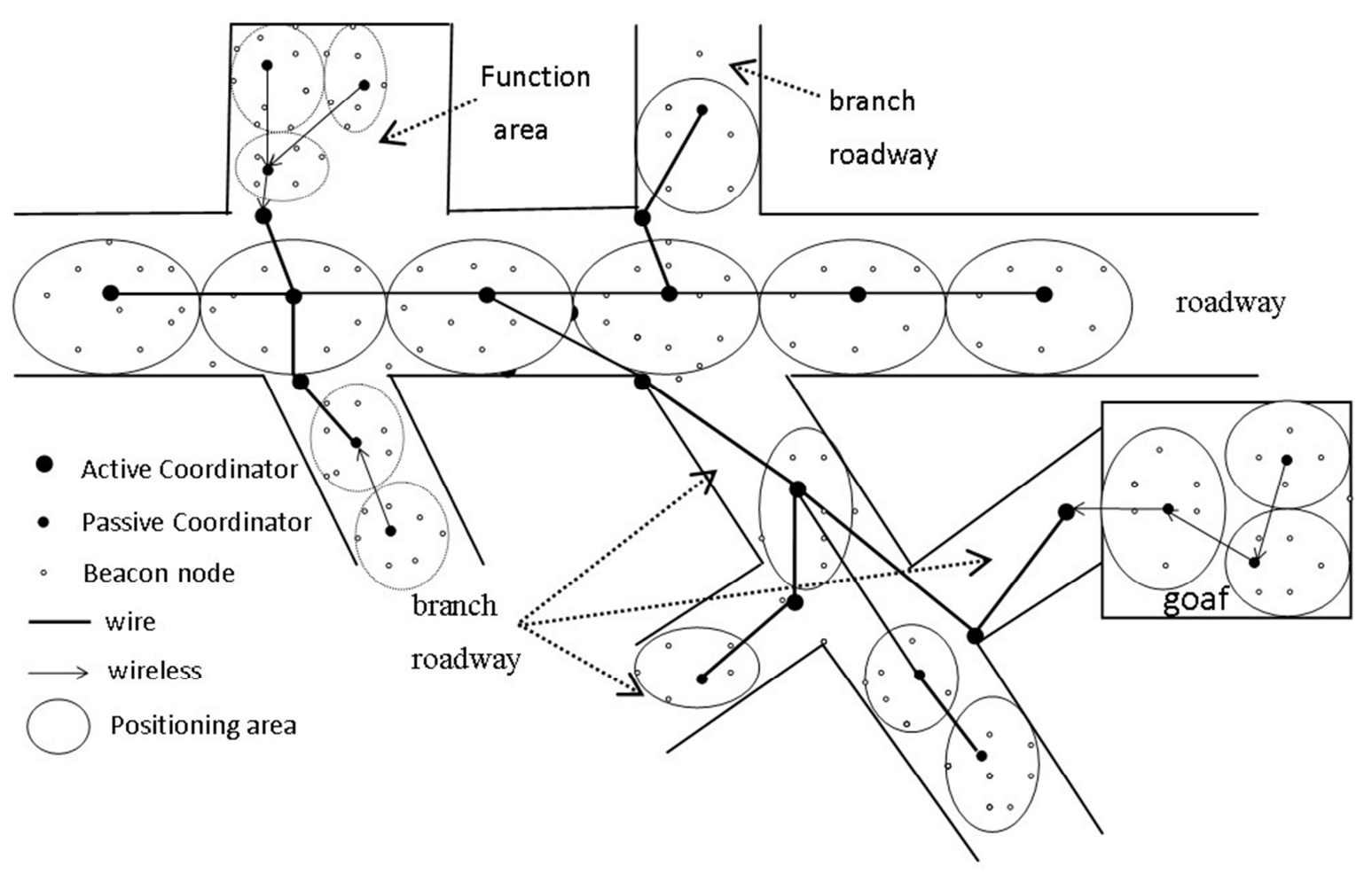

Figure 1. Layout diagram of underground positioning nodes.

\section{Realization of Underground Positioning}

The underground environment of coal mine is different from the ground, the indoor environment, the space is narrow and closed, the multi-path effect of the wireless signal is obvious, the electromagnetic wave is absorbed by the surrounding environment obviously. The noise generated by machinery and equipment and the frequent movement of people restrict the positioning accuracy. In order to achieve efficient and practical personnel positioning, it is best to adopt effective node layout strategy and effective positioning method according to the specific positioning requirements of the positioning site.

\subsection{Positioning Method for Goaf}

Goaf refers to the cavities left after underground mining is completed. In recent years, gas explosion accidents often occur in goaf, the main reason is that some managers and staff ignore the regulations for goaf, enter the goaf illegally and carry out unsafe behavior. The goaf area is large, the interference source of electromagnetic wave transmission is less, and the geological environment is stable [9]. The main focus of the positioning of the goaf personnel are as follows: (1) recording the information of the people entering the goaf, as the basis of workers who violate the rules. (2) determining the general position of the persons entering the goaf.

Install a coordinator at the entrance of the goaf, and install a reference node every 20 meters in the goaf [4]. The traditional triangulation algorithm based on RSSI is used in goaf. It is the transmission power of a given transmitting node. It measures the received power at the receiving point, calculates the transmission loss of radio waves, and converts the transmission loss into distance using theory or experience [10].

The wireless signal transmission model is described as follow [11]:

$$
\mathrm{P}_{\mathrm{r}, \mathrm{dB}}(\mathrm{d})=\mathrm{P}_{\mathrm{r}, \mathrm{dB}}\left(\mathrm{d}_{0}\right)-\eta 10 \lg \left\{\frac{\mathrm{d}}{\mathrm{d}_{0}}\right\}+\mathrm{X}_{\delta, \mathrm{dB}}
$$

Where $\mathrm{P}_{\mathrm{r}, \mathrm{dB}}(\mathrm{d})$ denotes the received power on the

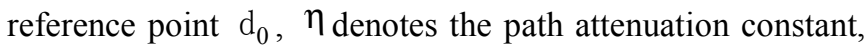
which needs to be calculated according to the field environment measurement, and $\eta \geq 2$ was obtained according to experience. The selection value of this example is $\eta=3 . X_{\delta, d B}$ is the normal part of the variance of $\delta^{2}$. In order to verify the positioning effect, a subway tunnel is selected to simulate the underground environment. The resulting data are shown in Table 1. 
Table 1. Positioning Test Result of Goaf.

\begin{tabular}{|c|c|c|c|c|}
\hline located target id & Actual coordinate & Measured position & Horizontal coordinate error & vertical coordinate error \\
\hline Target 1 & $(0.0,1.0)$ & $(0.3,1.7)$ & 0.3 & 0.7 \\
\hline Target 2 & $(0.0,3.0)$ & $(0.5,2.4)$ & 0.5 & 0.6 \\
\hline Target 3 & $(10.0,1.0)$ & $(10.8,1.8)$ & 0.8 & 0.8 \\
\hline Target 4 & $(10.0,3.0)$ & $(11.1,3.7)$ & 1.1 & 0.7 \\
\hline Target 5 & $(20.0,1.0)$ & $(21.1,1.6)$ & 1.1 & 0.6 \\
\hline Target 6 & $(20.0,3.0)$ & $(21.7,3.5)$ & 1.7 & 0.5 \\
\hline Target 7 & $(30.0,1.0)$ & $(28.7,2.2)$ & 1.3 & 1.2 \\
\hline Target 9 & $(40.0,1.0)$ & $(41.3,1.5)$ & 1.3 & 0.5 \\
\hline Target 10 & $(40.0,3.0)$ & $(41.4,3.8)$ & 1.4 & 0.8 \\
\hline
\end{tabular}

It can be seen from the data that 10 sampling data are listed. The maximum error of the horizontal coordinate is 2.0 meter, the minimum error is 0.3 meter, the average error of the horizontal coordinate is 1.15 meter, the maximum error of the vertical coordinate is 1.2 meter, the minimum error is 0.5 meter, the average error of the vertical coordinate is 0.75 meter, the error of the horizontal and vertical coordinates is large. For the goaf, such a meter-level positioning accuracy is acceptable.

\subsection{Positioning Method of Chamber}

The chamber is a kind of horizontal tunnel with large cross section and short length. Its role is to be installed various equipment and machinery, storage materials and tools, or for other special purposes. The electromagnetic environment of the chamber is changeable, but relatively stable. The main points of the personnel orientation of the chamber are as follows: (1) recording the information of the person entering the chamber. (2) determine the exact position of the person entering the chamber.

Common chambers may be placed winch rooms, substations, coal bunker repair rooms, explosive depots, lounges and shelters etc. The geographical environment of each chamber is similar, but the electromagnetic environment is very different. The precise positioning can be realized only by adopting the corresponding positioning method according to the specific electromagnetic environment.

A coordinator is installed at the entrance of the goaf, and a reference node is installed every 10 meter in the chamber. In order to improve the positioning accuracy, the RSSI value needs to be corrected. The chamber adopts modified RSSI value for positioning. The localization algorithm adopts three sides localization combined with centroid positioning algorithm.

In underground environment, the RSSI value between nodes will be affected by many factors, such as temperature, humidity, obstacles, geographical environment, electromagnetism and so on [12]. There is a big deviation in calculating the distance according to the RSSI value between nodes.

Reduce the ranging error, and then improve the positioning accuracy. The modified RSSI value is shown in figure 2 .

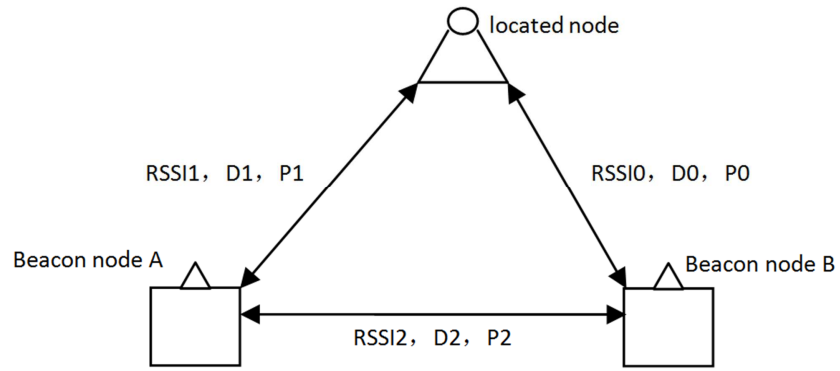

Figure 2. Modified RSSI Value.

Where the symbol RSSI1 denotes the distance between located node and beacon node A. P1 denotes the located node's received power value $(\mathrm{mW})$ from the beacon node A. D1 denotes the located node's received intensity value $(\mathrm{dBm})$ from the beacon node $\mathrm{A}$. the symbol RSSI2 denotes the distance between beacon node $\mathrm{A}$ and beacon node B. P2 denotes the beacon node A's received power value $(\mathrm{mW})$ from the beacon node B. D2 (known) denotes the beacon node A's received intensity value $(\mathrm{dBm})$ from the beacon node $B$. The relationship between D1 and D2 is described as follow:

$$
\mathrm{D} 1=\mathrm{D} 2 * 10^{\left(\mathrm{P}_{1}-\mathrm{P}_{2}\right) / 10 * \mathrm{k}}
$$

Where $\mathrm{k}$ has a range of 3.25-4.5, and in this case, $\mathrm{K}=4.0$.

In the positioning algorithm, the centroid localization algorithm was added to the three edge positioning algorithm for improving localization accuracy. The algorithm is described in Figure 3.

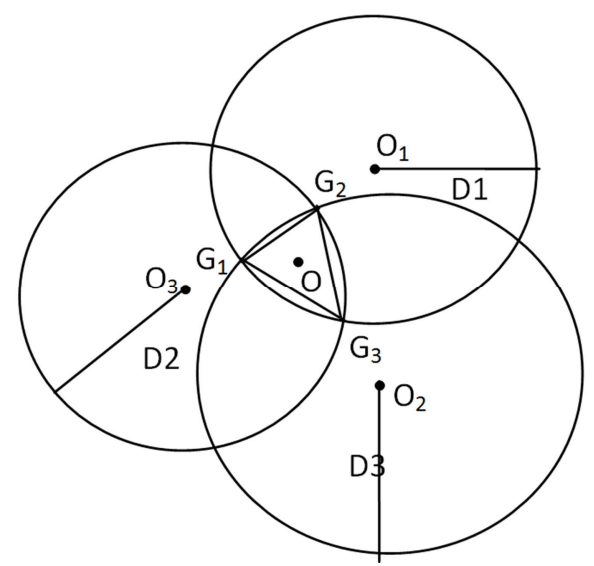

Figure 3. Algorithm improvement schematic diagram. 
Where the beacon nodes are $\mathrm{O}_{1}, \mathrm{O}_{2}$ and $\mathrm{O}_{3}$ and their coordinates are $\left(\mathrm{x}_{1}, \mathrm{y}_{1}\right),\left(\mathrm{x}_{2}, \mathrm{y}_{2}\right)$ and $\left(\mathrm{x}_{3}, \mathrm{y}_{3}\right)$ respectively. The distance from the blind node to the three beacon nodes is D1, $\mathrm{D} 2, \mathrm{D} 3$. The circle of $\mathrm{O} 1, \mathrm{O} 2$, and $\mathrm{O} 3$ intersects at point $\mathrm{G} 1$, $\mathrm{G} 2, \mathrm{G} 3$ and their coordinates are $\left(\mathrm{x}_{\mathrm{G} 1}, \mathrm{y}_{\mathrm{G} 1}\right),\left(\mathrm{x}_{\mathrm{G} 2}, \mathrm{y}_{\mathrm{G} 2}\right),\left(\mathrm{x}_{\mathrm{G} 3}, \mathrm{y}_{\mathrm{G} 3}\right)$ respectively. According to the following formula, we can calculate the coordinate of G1, G2 and G3.

$$
\left\{\begin{array}{l}
\sqrt{\left(x_{\mathrm{G} 1}-\mathrm{x}_{1}\right)^{2}+\left(\mathrm{y}_{\mathrm{G} 1}-\mathrm{y}_{1}\right)^{2}}=\mathrm{D}_{1} \\
\sqrt{\left(\mathrm{x}_{\mathrm{G} 1}-\mathrm{x}_{2}\right)^{2}+\left(\mathrm{y}_{\mathrm{G} 1}-\mathrm{y}_{2}\right)^{2}}=\mathrm{D}_{2} \\
\sqrt{\left(\mathrm{x}_{\mathrm{G} 1}-\mathrm{x}_{3}\right)^{2}+\left(\mathrm{y}_{\mathrm{G} 1}-\mathrm{y}_{3}\right)^{2}}=\mathrm{D}_{3}
\end{array}\right.
$$

$\mathrm{G}_{1}, \mathrm{G}_{2}$ and $\mathrm{G}_{3}$ compose $\Delta \mathrm{G}_{1} \mathrm{G}_{2} \mathrm{G}_{3}, \mathrm{O}$ is the centroid of $\Delta \mathrm{G}_{1} \mathrm{G}_{2} \mathrm{G}_{3}$. Its coordinate $\left(\mathrm{x}_{0}, \mathrm{y}_{0}\right)$ is the blind node coordinate..

$$
\left\{\begin{array}{l}
\mathrm{x}_{0}=\frac{\mathrm{x}_{\mathrm{G} 1}+\mathrm{x}_{\mathrm{G} 2}+\mathrm{x}_{\mathrm{G} 3}}{3} \\
\mathrm{y}_{0}=\frac{\mathrm{y}_{\mathrm{G} 1}+\mathrm{y}_{\mathrm{G} 2}+\mathrm{y}_{\mathrm{G} 3}}{3}
\end{array}\right.
$$

In order to verify the positioning effect, a subway tunnel is selected to simulate the underground environment. The resulting data are shown in Table 2.

\begin{tabular}{|c|c|c|c|c|}
\hline located target id & Actual coordinate & Measured coordinate & Horizontal coordinate error & Vertical coordinate error \\
\hline Target 1 & $(0.0,1.0)$ & $(0.2,1.1)$ & 0.2 , & 0.1 \\
\hline Target 2 & $(0.0,4.0)$ & $(0.2,4.3)$ & 0.2 & 0.3 \\
\hline Target 3 & $(0.0,8.0)$ & $(0.3,8.4)$ & 0.3 & 0.4 \\
\hline Target 5 & $(4.0,4.0)$ & $(4.0,4.1)$ & 0.0 & 0.1 \\
\hline Target 6 & $(4.0,8.0)$ & $(4.4,8.5)$ & 0.4 & 0.5 \\
\hline Target 7 & $(8.0,1.0)$ & $(8.3,1.2)$ & 0.3 & 0.2 \\
\hline Target 9 & $(8.0,8.0)$ & $(8.2,8.0)$ & 0.2 & 0.0 \\
\hline
\end{tabular}

Table 2. Positioning Test Result of Chamber:

It can be seen from the experimental data that 9 sampling data are listed. The maximum error of the horizontal coordinate is 0.4 meter, the minimum error is 0.0 meter. the average error of the ordinate is 0.23 meter, the maximum error of the ordinate is 1.5 meter, the minimum error is 0.0 meter. The average error of the ordinate is 0.27 meter. The errors in the vertical coordinates are small. Such positioning accuracy is acceptable in the chamber.

\subsection{Positioning Method of Roadway}

Roadway generally refers to underground mining, for mining lifting, transportation, ventilation, drainage, power supply and so on [4].

The roadway alternately overlaps, is intricate, the length may reach several kilometers even tens of thousands meters
[13]. The requirement of roadway positioning is to realize the positioning of the static personnel and the mobile personnel in the roadway. The tunnel is narrow and slender, which is not conducive to the deployment of beacon nodes. Therefore, the beacon nodes in the underground roadway are all deployed in a chain intensive manner. The beacon nodes are installed only on the side of the pillar, and in the main roadway.

Each beacon node can communicate with at least four adjacent nodes because of the uniform spacing and dense density of the beacon nodes, and the beacon nodes in the tunnel can be numbered continuously [14].

Using the same positioning method as chamber positioning, the underground environment is simulated through a subway construction tunnel [15]. The experimental data obtained from the stationary and moving objects are shown in Table 3.

\begin{tabular}{|c|c|c|c|c|c|}
\hline $\begin{array}{l}\text { Blind } \\
\text { node id }\end{array}$ & $\begin{array}{l}\text { Actual } \\
\text { coordinate }\end{array}$ & $\begin{array}{l}\text { Measured coordinate } \\
\text { (stillness) }\end{array}$ & $\begin{array}{l}\text { Measured coordinate } \\
(\mathrm{moving} \text { speed } 1 \mathrm{~m} / \mathrm{s})\end{array}$ & $\begin{array}{l}\text { Horizontal coordinate error } \\
\text { (stillness) }\end{array}$ & $\begin{array}{l}\text { vertical coordinate error } \\
\text { (stillness) }\end{array}$ \\
\hline Target 1 & $(0.0,1.0)$ & $(0.2,1.1)$ & $(0.2,1.2)$ & 0.2 & 0.1 \\
\hline Target 2 & $(0.0,3.0)$ & $(0.4,3.5)$ & $(0.4,3.4)$ & 0.4 & 0.5 \\
\hline Target 3 & $(0.0,5.0)$ & $(0.0,5.1)$ & $(0.3,5.3)$ & 0.0 & 0.3 \\
\hline Target 4 & $(20.0,1.0)$ & $(21.0,1.0)$ & $(21.1,1.0)$ & 1.0 & 0.0 \\
\hline Target 5 & $(20.0,3.0)$ & $(20.7,3.2)$ & $(20.6,3.3)$ & 0.6 & 0.3 \\
\hline Target 6 & $(20.0,5.0)$ & $(20.9,5.4)$ & $(20.7,5.4)$ & 0.7 & 0.4 \\
\hline Target 8 & $(40.0,3.0)$ & $(41.0,3.5)$ & $(40.6,3.6)$ & 0.6 & 0.5 \\
\hline Target 9 & $(40.0,5.0)$ & $(40.8,5.6)$ & $(40.7,5.6)$ & 0.8 & 0.6 \\
\hline Target 10 & $(60.0,1.0)$ & $(60.7,1.3)$ & $(60.4,1.4)$ & 0.7 & 0.3 \\
\hline Target 11 & $(60.0,3.0)$ & $(60.0,2.8)$ & $(60.0,2.8)$ & 0.0 & 0.2 \\
\hline Target 12 & $(60.0,5.0)$ & $(60.9,5.6)$ & $(60.8,5.6)$ & 0.9 & 0.6 \\
\hline Target 13 & $(80.0,1.0)$ & $(80.5,1.5)$ & $(80.5,1.5)$ & 0.5 & 0.5 \\
\hline Target 14 & $(80.0,3.0)$ & $(80.8,3.6)$ & $(80.6,3.6)$ & 0.8 & 0.6 \\
\hline
\end{tabular}

Table 3. Positioning Test Result of Roadway. 
It can be seen from the experimental data that 15 sampling data are listed. The maximum error of the horizontal coordinate is 1.7 meter, the minimum error is 0.0 meter. the average error of the coordinate is 0.63 meter, the maximum error of the vertical coordinate is 0.7 meter, the minimum error is 0.0 meter and the average error of the vertical coordinate is 0.37 meter. If we take into account the factors such as human walking and column occlusion in the actual environment, the error will inevitably increase or even double, but for roadway positioning, the error can be controlled at the meter level, so the positioning accuracy of the meter level can be accepted.

\section{Conclusion}

The coal in China is mostly underground mining, and the geological conditions are complicated [16]. Safety production is an important requirement of coal production. In the technology of ensuring safe production, the positioning of underground personnel is more and more important. The underground communication environment of coal mine is complex and the difference is easy to be affected by the surrounding environment. In order to achieve efficient localization, RSSI algorithm and trilateral localization algorithm are adopted according to the characteristics and requirements of specific application environment. According to the specific environment, the RSSI is modified, and the centroid positioning algorithm is added on the basis of the trilateral localization algorithm, which improves the accuracy of the positioning. It is proved by test that the positioning accuracy can be satisfied. The positioning requirement can be used as a reference for underground positioning ring in coal mine.

\section{References}

[1] Lee Hojae, Lee Sanghoon, Kim Yeonsoo,"A localization algorithm using space information for indoor wireless sensor networks, International Conference on Advanced Communication Technology, ICACT, 2009, v1, p725-728.

[2] Jia Qiuting, Zhang Shen, Hu Qingsong, "An energy-balancing deployment strategy of WSNs used in mine roadway," Joural of China University of Mining \&Technology, 2015, 44 (4):761-768.

[3] Sugano Masashi, Kawazoe Tomonori, Ohta Yoshikazu, et, "Indoor localization system using RSSI measurement of wireless sensor network based on ZigBee standard", the Sixth IASTED International Multi-Conference on Wireless and Optical Communications, 2006.

[4] SUN Jiping," Characteristics of coal mine accidents and new technologies of coal mine communication, personnel positioning and monitoring," Industry and Mine Automation, 2015, $41(2): 1-5$.

[5] Sun Zhexing,"Personnel positioning method in underground coal mine,"Coal Science and Technology, 2018, 46 (3):130-134.

[6] Li Baozhu, Wang Hui," A low complexity localization algorithm in wireless sensor Network", 2010 Asia-Pacific Conference on Information Technology and Ocean Engineering, 2010, p217-220.

[7] GAO L, ZHU M, YANG D," Simulation and Implement of Weighted Centroid Localization Algorithm Based on ZigBee," Chinese Journal of Sensors and Actuators, 2010, 1: 32.

[8] Tian Jinpeng, Zheng Guoxin, Wang Keqian,"Application of wireless sensor network in mine monitoring system", ICALIP 2010-2010 International Conference on Audio, Language and Image Processing, Proceedings, 2010, p263-268.

[9] Sun Zhexing, "Research on mine personnel positioning method based on time range," Industry and Mine Automation, 2018, 44 (4):30-33.

[10] Ganggang Yu, Fengqi Yu, "A localization algorithm for mobile wireless sensor networks", IEEE ICIT 2007. 2007 IEEE International Conference on Integration Technology, 2007, p623-627.

[11] Chen P H, Shastry M C, Lai C P, "A portable real-time digital noise radar system forthrough-the-wall imaging". Geoscience and Remote Sensing, IEEE Transactions on, 2012, 50 (10): 4123-4134.

[12] Amundson I, Sallai J, Koutsoukos X, "RF angle of arrival-based node localisation", International Journal of Sensor Networks, 2011, 9 (3): 209-224.

[13] Gunay F B, Cavdar T, "Mobile fleet localization model via RSSI, TOA and TDOA in wireless sensor networks," Signal Processing and Communications Applications Conference (SIU), 2014 22nd. IEEE, 2014: 1431-1434.

[14] Niculescu D, Nath B, "DV based positioning in ad hoc networks", Telecommunication Systems, 2003, 22 (1-4): 267-280.

[15] Bulusu N, Heidemann J, Estrin D,"GPS-less low-cost outdoor localization for very small Devices," Personal Communications, IEEE, 2000, 7 (5): 28-34.

[16] GAO L, ZHU M, YANG D," Simulation and Implement of Weighted Centroid Localization Algorithm Based on Zig Bee," Chinese Journal of Sensors and Actuators, 2010, 1: 32.

\section{Biography}

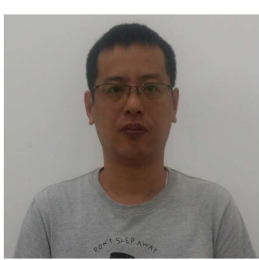

intelligence.
Ru Yandong (1980-) $\mathrm{He}$ is an associate professor of Heilongiang University of Science and Technology. He is a doctoral student in Heilongjiang University. He has published 10 articles in public. His research direction is: coal mine safety, artificial 